\title{
Doping fin field-effect transistor sidewalls : impurity dose retention in silicon due to high angle incident ion implants and the impact on device performance
}

\author{
Citation for published version (APA): \\ Duffy, R., Curatola, G., Pawlak, B. J., Doornbos, G., Tak, van der, K., Breimer, P., Berkum, van, J. G. M., \& \\ Roozeboom, F. (2008). Doping fin field-effect transistor sidewalls: impurity dose retention in silicon due to high \\ angle incident ion implants and the impact on device performance. Journal of Vacuum Science and Technology, \\ $B, 26(1), 402-407$. https://doi.org/10.1116/1.2816925
}

DOI:

10.1116/1.2816925

Document status and date:

Published: 01/01/2008

\section{Document Version:}

Publisher's PDF, also known as Version of Record (includes final page, issue and volume numbers)

\section{Please check the document version of this publication:}

- A submitted manuscript is the version of the article upon submission and before peer-review. There can be important differences between the submitted version and the official published version of record. People interested in the research are advised to contact the author for the final version of the publication, or visit the $\mathrm{DOI}$ to the publisher's website.

- The final author version and the galley proof are versions of the publication after peer review.

- The final published version features the final layout of the paper including the volume, issue and page numbers.

Link to publication

\footnotetext{
General rights

- You may freely distribute the URL identifying the publication in the public portal. follow below link for the End User Agreement:

www.tue.nl/taverne

\section{Take down policy}

If you believe that this document breaches copyright please contact us at:

openaccess@tue.nl

providing details and we will investigate your claim.
}

Copyright and moral rights for the publications made accessible in the public portal are retained by the authors and/or other copyright owners and it is a condition of accessing publications that users recognise and abide by the legal requirements associated with these rights.

- Users may download and print one copy of any publication from the public portal for the purpose of private study or research.

- You may not further distribute the material or use it for any profit-making activity or commercial gain

If the publication is distributed under the terms of Article $25 \mathrm{fa}$ of the Dutch Copyright Act, indicated by the "Taverne" license above, please 


\title{
Doping fin field-effect transistor sidewalls: Impurity dose retention in silicon due to high angle incident ion implants and the impact on device performance
}

\author{
R. Duffy, ${ }^{a), b)}$ G. Curatola, ${ }^{\text {b) }}$ B. J. Pawlak, ${ }^{\text {b) }}$ and G. Doornbos ${ }^{\text {b) }}$ \\ NXP Semiconductors, Kapeldreef 75, 3001 Leuven, Belgium \\ K. van der Tak, P. Breimer, and J. G. M. van Berkum \\ Philips Research Laboratories Eindhoven, High Tech Campus 11, 5656 AE Eindhoven, The Netherlands \\ F. Roozeboom \\ NXP Semiconductors, High Tech Campus 4, 5656 AE Eindhoven, The Netherlands
}

(Received 17 May 2007; accepted 30 October 2007; published 31 January 2008)

\begin{abstract}
The three dimensional (3D) nature of a fin field-effect transistor (FinFET) structure creates new challenges for an impurity doped region formation. For the triple gate FinFET, both top and side surfaces require high levels of dopant incorporation to minimize access resistance. In this work, we investigate the use of conventional ion implantation for the introduction of impurities in this 3D silicon structure. Specifically, we evaluate sidewall impurity dose retention at various angles of incidence. The retention of dose is determined by (i) trigonometry of the implant angle in the 3D fin system, (ii) backscattering, and (iii) material properties of the target surface. Dose retention is most sensitive to the implant angle. For a fixed implant projected range, lighter ions are more likely to be ejected from the target. Thus, heavier ions are better for dose retention. The influence of sidewall dose retention on the electrical performance of fully depleted FinFETs was investigated by means of 3D device simulation. Drive current and short channel effect control are more sensitive to dose retention on sidewalls than to dopant conformality. (C) 2008 American Vacuum Society.
\end{abstract}

[DOI: $10.1116 / 1.2816925]$

\section{INTRODUCTION}

Scaling metal-oxide-semiconductor (MOS) devices to sub-30-nm gate lengths is a complex challenge, given the increased difficulty of controlling short channel effects (SCEs) and off-state leakage. In this regard, multigate MOS devices such as FinFETs have proven to be a promising approach. ${ }^{1-3}$ However, as the width of this device can be approximated as the sum of the side and the top surface dimensions, optimization of the side surface (sidewall) doping can add an extra degree of freedom for an improved FinFET performance. A conformal deposition and indiffusion methodology may produce equal doping on top and side surfaces, and techniques such as vapor phase doping and chemical vapor deposition could be advantageous in this regard. However, ion implantation remains a strong candidate as the means to introduce dopants into the fin, as it is an established and conventional technique. One disadvantage is the angle restriction to avoid shadowing during implant of dense structures. The fin height to spacing ratio and the resist height determine the maximum implant angle so that the ion beam hits the foot of each fin. Failure to do so leads to an increase in access resistance and, consequently, to a loss in drive current. In this work, we evaluate the key ion implantation parameters that affect FinFET sidewall doping retention. Note that the device structure under investigation is the

\footnotetext{
${ }^{a)}$ Electronic mail: ray.duffy@nxp.com

${ }^{b}$ Present address: NXP-TSMC Research Center, Kapeldreef 75, 3001 Leuven, Belgium
}

fully depleted FinFET that has an undoped channel and doping performed self-aligned to the gate electrode.

Due to the three dimensional (3D) nature of the FinFET, major challenges arise for junction characterization. Two orientations exist, and while they are not entirely independent, the top surface doping profile may differ significantly from that on the side. Thus, characterization of the sidewall doping becomes a pressing issue. Accessing the sidewall is a difficult task, and some recent work has done so through cross-sectioning the fin. ${ }^{4}$ Here, we mimic the FinFET sidewall system by implanting at various tilt angles on bulk silicon wafers, in order to facilitate secondary ion mass spectroscopy (SIMS) analysis with a fast turnaround time. Experiments were compared to simulations for further analysis and interpretation of the results.

\section{EXPERIMENT}

Samples from (100) wafers were placed on mounting faces with different angles, namely, $5^{\circ}, 30^{\circ}, 60^{\circ}, 70^{\circ}$, or $80^{\circ}$, and a single implant was performed. No dose correction was applied; i.e., the maximum dose retention possible in this case was $\cos$ (tilt angle). Boron, phosphorus, arsenic, and antimony were implanted to a dose of $1 \times 10^{15} \mathrm{~cm}^{-2}$ with energies of 2, 4, 5, and $6 \mathrm{keV}$, respectively, so all profiles had the same projected range $\left(R_{P}\right)$. In this way, we determine if dose retention is correlated with impurity species mass, for a fixed $R_{P}$. Arsenic was further implanted to a dose of $1 \times 10^{15} \mathrm{~cm}^{-2}$ with energies of 3 and $7 \mathrm{keV}$ to investigate if 


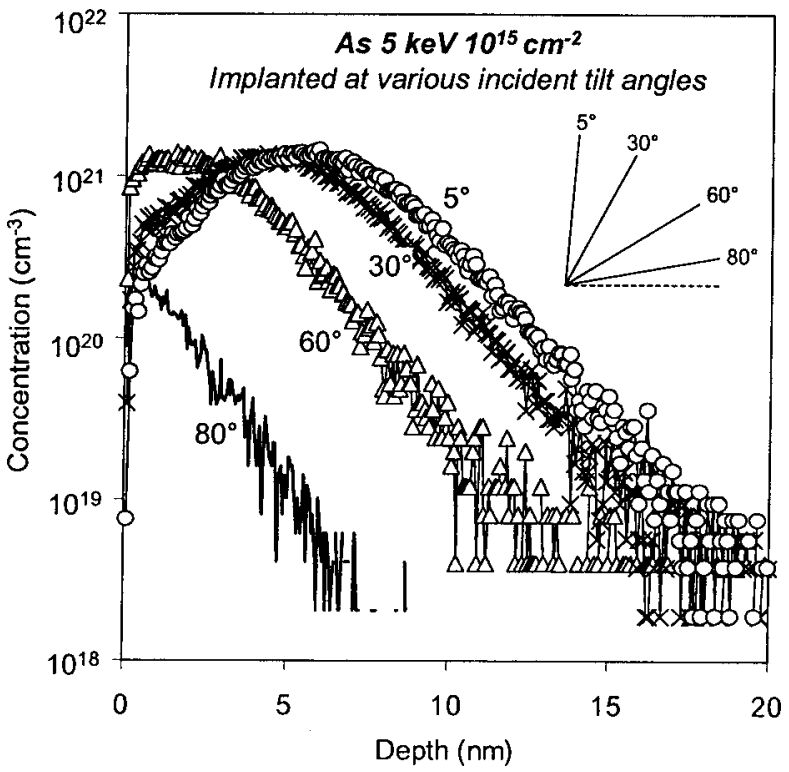

FIG. 1. SIMS profiles for arsenic $1 \times 10^{15} \mathrm{~cm}^{-2} 5 \mathrm{keV}$ implants with tilt angles of $5^{\circ}, 30^{\circ}, 60^{\circ}$, and $80^{\circ}$. Higher tilt angles mean less dose incorporated and a shallower profile. The retained doses are $82 \%, 59 \%$, and $5.0 \%$ of the specified dose for $30^{\circ}, 60^{\circ}$, and $80^{\circ}$, respectively.

dose retention is correlated with $R_{P}$, for a fixed impurity mass. Some samples received a $1050{ }^{\circ} \mathrm{C}$ rapid thermal anneal (RTA) in an inert $\mathrm{N}_{2}$ ambient.

\section{RESULTS}

Figure 1 shows SIMS profiles for arsenic $1 \times 10^{15} \mathrm{~cm}^{-2}$ $5 \mathrm{keV}$ implants with different tilt angles. Clearly, the incident angle has a significant impact on the implanted profile in terms of retained dose and depth. In this case, the retained doses are $82 \%, 59 \%$, and $5.0 \%$ of the specified dose for $30^{\circ}$, $60^{\circ}$, and $80^{\circ}$, respectively. The profiles after a $1050^{\circ} \mathrm{C}$ RTA are shown in Fig. 2. The depths at a concentration level of $5 \times 10^{18} \mathrm{~cm}^{-3}$ are $37,29,16$, and $9 \mathrm{~nm}$. The diffusion of arsenic in these conditions is largely driven by high concentration effects; ${ }^{5,6}$ thus, more retained dose means more diffusion. Careful optimization is therefore necessary to avoid short channel effect control degradation.

Figure 3 shows SIMS profiles for antimony 1 $\times 10^{15} \mathrm{~cm}^{-2} 6 \mathrm{keV}$ implants with tilt angles of $5^{\circ}, 60^{\circ}, 70^{\circ}$, and $80^{\circ}$. Again, higher tilt angles mean less dose incorporated and a shallower profile. The retained doses are $50 \%$, $28 \%$, and $8.6 \%$ of the specified dose for $60^{\circ}, 70^{\circ}$, and $80^{\circ}$, respectively.

Figure 4 shows SIMS profiles for phosphorus 1 $\times 10^{15} \mathrm{~cm}^{-2} 4 \mathrm{keV}$ implants with tilt angles of $5^{\circ}, 60^{\circ}, 70^{\circ}$, and $80^{\circ}$. The retained doses are $43 \%, 24 \%$, and $7.6 \%$ of the specified dose for $60^{\circ}, 70^{\circ}$, and $80^{\circ}$, respectively.

Figure 5 shows SIMS profiles for boron $1 \times 10^{15} \mathrm{~cm}^{-2}$ $2 \mathrm{keV}$ implants with tilt angles of $5^{\circ}, 60^{\circ}, 70^{\circ}$, and $80^{\circ}$. The retained doses are $31 \%, 15 \%$, and $4.9 \%$ of the specified dose for $60^{\circ}, 70^{\circ}$, and $80^{\circ}$, respectively.

In Fig. 6 is an overlay of the SIMS profiles with $5^{\circ}$ tilt implantation and with $80^{\circ}$ tilt implantation in the inset. This

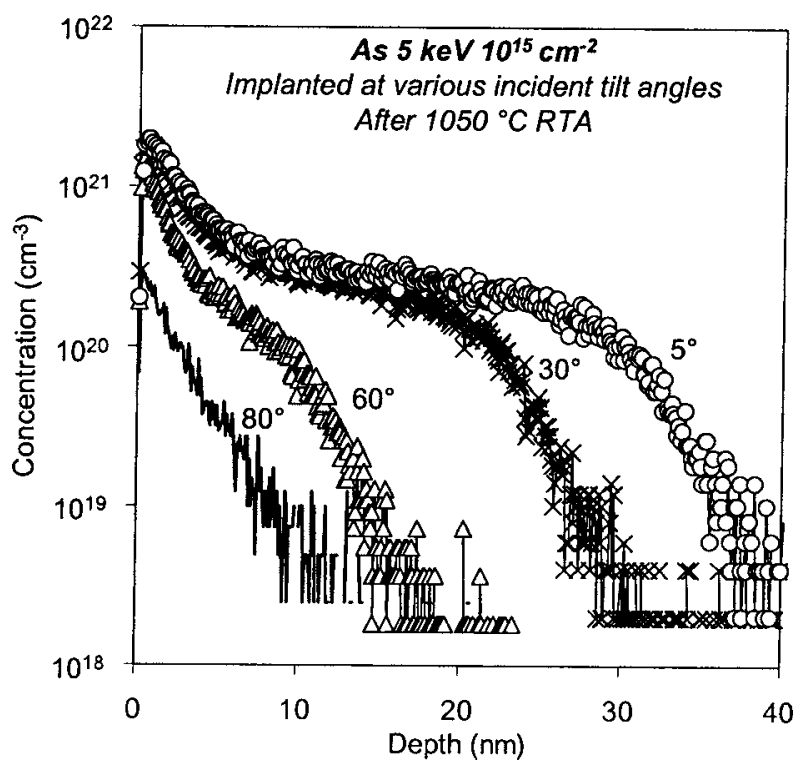

FIG. 2. SIMS profiles for arsenic implants shown in Fig. 1 after a $1050{ }^{\circ} \mathrm{C}$ RTA. The depths at a concentration level of $5 \times 10^{18} \mathrm{~cm}^{-3}$ are $37,29,16$, and $9 \mathrm{~nm}$ for the implant tilt angles of $5^{\circ}, 30^{\circ}, 60^{\circ}$, and $80^{\circ}$, respectively.

overlay highlights the effect of ion mass on the implanted distribution for a fixed $R_{P}$. The heavier antimony ion produces a relatively well-confined profile. The light boron ion produces a relatively diffuse spread-out profile. This is clear in the $5^{\circ}$ tilt profiles, less obvious in the $80^{\circ}$ tilt profiles as the retained dose is lower. In summary, longitudinal straggle during ion implant depends on ion mass.

For arsenic implanted with different energies between 3 and $7 \mathrm{keV}$, unfortunately, we did not observe a clear trend in

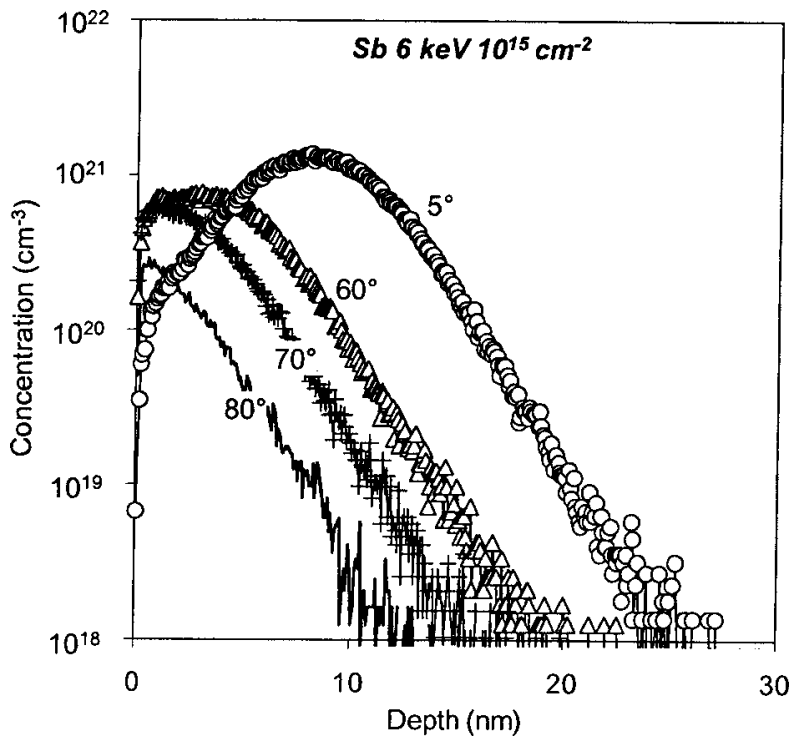

FIG. 3. SIMS profiles for antimony $1 \times 10^{15} \mathrm{~cm}^{-2} 6 \mathrm{keV}$ implants with tilt angles of $5^{\circ}, 60^{\circ}, 70^{\circ}$, and $80^{\circ}$. Higher tilt angles mean less dose incorporated and a shallower profile. The retained doses are $50 \%, 28 \%$, and $8.6 \%$ of the specified dose for $60^{\circ}, 70^{\circ}$, and $80^{\circ}$, respectively. 


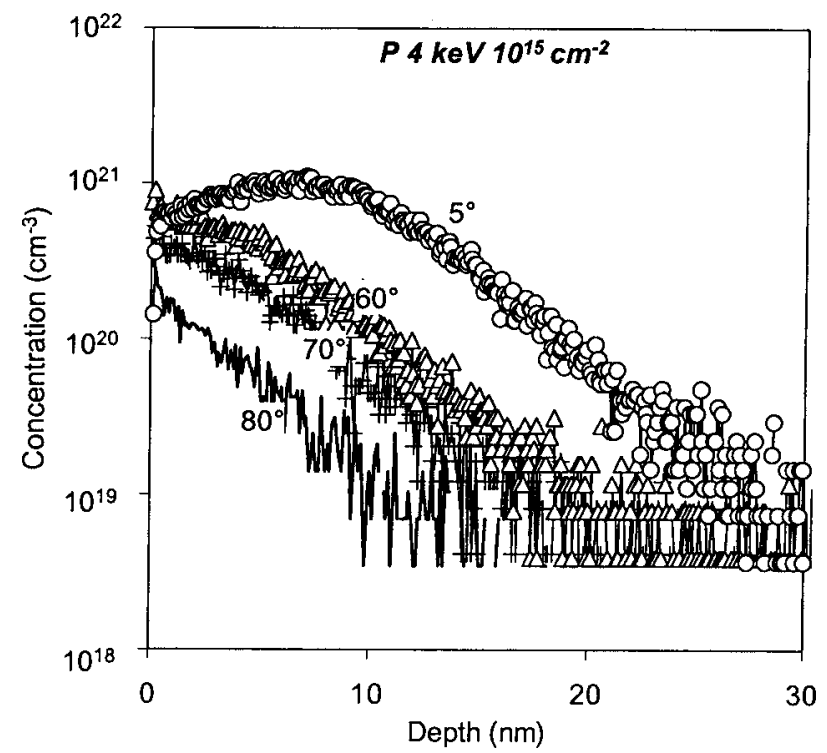

FIG. 4. SIMS profiles for phosphorus $1 \times 10^{15} \mathrm{~cm}^{-2} 4 \mathrm{keV}$ implants with tilt angles of $5^{\circ}, 60^{\circ}, 70^{\circ}$, and $80^{\circ}$. The retained doses are $43 \%, 24 \%$, and $7.6 \%$ of the specified dose for $60^{\circ}, 70^{\circ}$, and $80^{\circ}$, respectively.

dose retention. It is possible that dose retention is correlated with $R_{P}$ but that we did not investigate a wide enough range of implant energies in this experiment.

\section{DISCUSSION}

\section{A. SRIM simulations}

Dose retention on the sidewalls is most sensitive to the incident implant angle. This is reinforced by the summary graph in Fig. 7, where retained dose is plotted versus incident tilt angle. As the angle is increased, less dose is retained. Comparing different impurities for fixed $R_{P}$, the

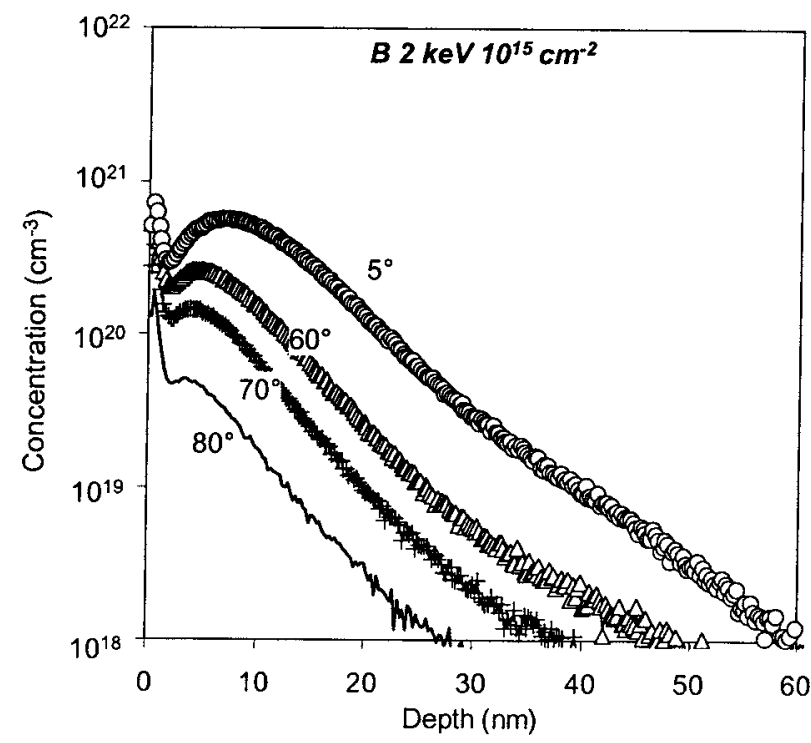

FIG. 5. SIMS profiles for boron $1 \times 10^{15} \mathrm{~cm}^{-2} 2 \mathrm{keV}$ implants with tilt angles of $5^{\circ}, 60^{\circ}, 70^{\circ}$, and $80^{\circ}$. The retained doses are $31 \%, 15 \%$, and $4.9 \%$ of the specified dose for $60^{\circ}, 70^{\circ}$, and $80^{\circ}$, respectively.

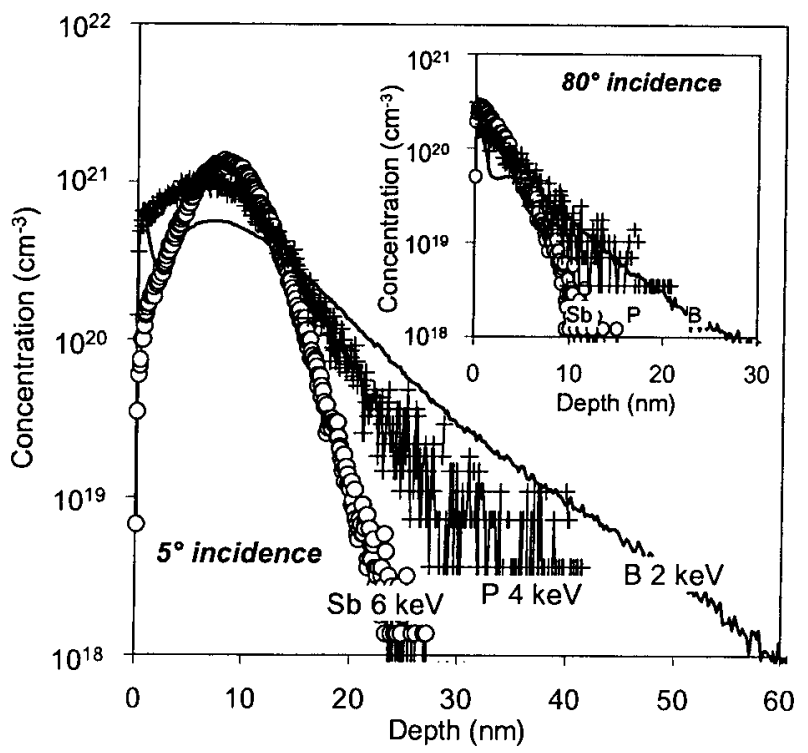

FIG. 6. SIMS overlay of the $5^{\circ}$ implants of antimony $1 \times 10^{15} \mathrm{~cm}^{-2} 6 \mathrm{keV}$, phosphorus $1 \times 10^{15} \mathrm{~cm}^{-2} 4 \mathrm{keV}$, and boron $1 \times 10^{15} \mathrm{~cm}^{-2} 2 \mathrm{keV}$. The inset shows the SIMS overlay for the corresponding $80^{\circ}$ implants.

heavier elements are better. Boron constantly has the lowest retained dose. The physical explanation for this trend was explored with the aid of the simulation program SRIM (the stopping and range of ions in matter). ${ }^{7}$

In SRIM, we specified calculations of full damage cascades, as well as surface sputtering of the target material. Note that the aim here was to extract trends, so we did not alter the ion distributions to account for the sputtering of the target material. Backscattering causes ion loss from the target material and can account for some of the discrepancy between theory and experiment. In the top half of Fig. 7 are plots of ion trajectories from SRIM simulations, for

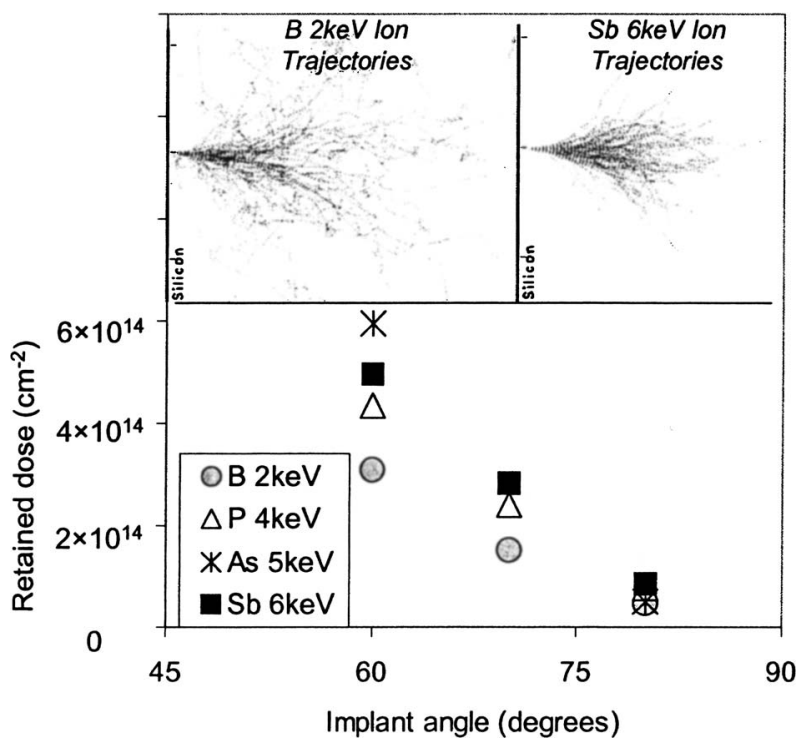

FIG. 7. Retained dose versus implant angle extracted from the SIMS profiles in Figs. 1 and 3-5. The upper half shows ion trajectories from SRIM simulations for $6 \mathrm{keV}$ antimony and $2 \mathrm{keV}$ boron implants. 


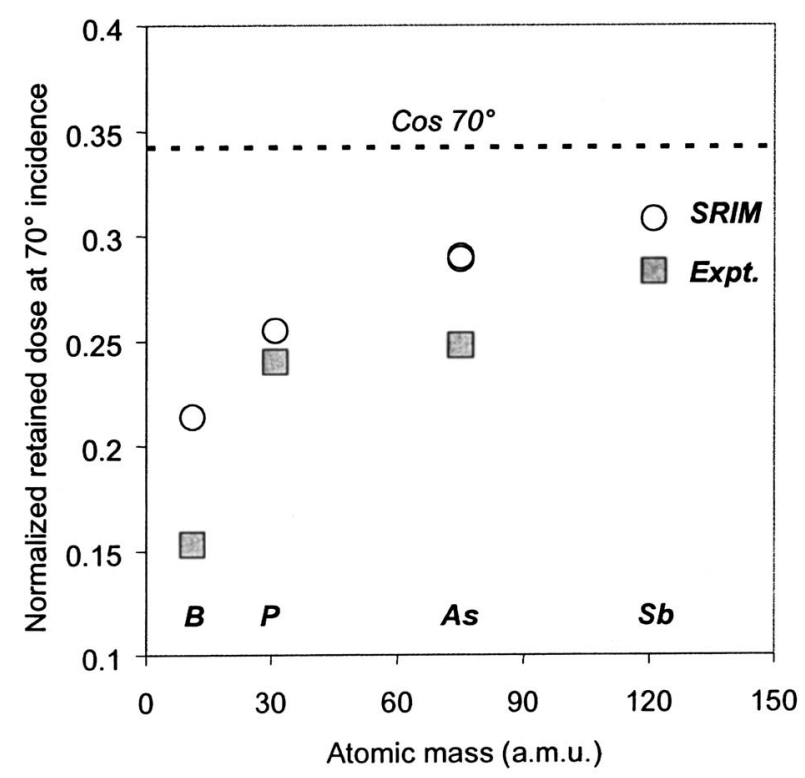

FIG. 8. Normalized dose retention at $70^{\circ}$ implant incidence vs ion mass. $\cos \left(70^{\circ}\right)$ is the maximum dose possible due to trigonometry here. SRIM qualitatively reproduces the experimental trend without calibration of surface properties.

$6 \mathrm{keV}$ antimony and $2 \mathrm{keV}$ boron implants. Straggling is more prominent for the lighter boron, and it is more likely that those ions will deflect back to the surface and thus escape.

The retention of dose on FinFET sidewalls is determined by (i) trigonometry of the implant angle in the 3D fin system, (ii) backscattering, and (iii) material properties of the target surface. This is represented in Fig. 8, where a normalized dose at $70^{\circ}$ incidence is plotted versus an atomic mass of the implanted impurities. $\cos \left(70^{\circ}\right)$ is 0.34 , and thus without dose correction during implant, trigonometry limits the maximum dose retention to $34 \%$. All the experimental data are below this value, boron only having $15 \%$ and antimony only $28 \%$ dose retention. With backscattering included in SRIM, the ion mass dependency of dose retention is reproduced qualitatively, if not quantitatively. Surface sputtering and the material properties of the surface could be used as a fitting parameter to further match the experimental data. The target surface will not be perfectly planar and will roughen due to the bombardment of the incident ions during implantation. These effects were not included in our simulations, as we did not attempt a calibration exercise. In a FinFET structure, additional nonuniformities may be present due to the etch of the 3D fin structure. Note that an accurate experimental impurity concentration quantification at the surface is not easy and may introduce another degree of uncertainty.

\section{B. Device simulations}

3D device simulations were undertaken to gain insight into the impact of sidewall doping concentration in FinFET device performance. User-specified fully depleted $n$-type MOS devices were defined in SENTAURUS DEVICE (Ref. 8) with a $60 \mathrm{~nm}$ fin height, $10 \mathrm{~nm}$ fin width, $30 \mathrm{~nm}$ gate length,

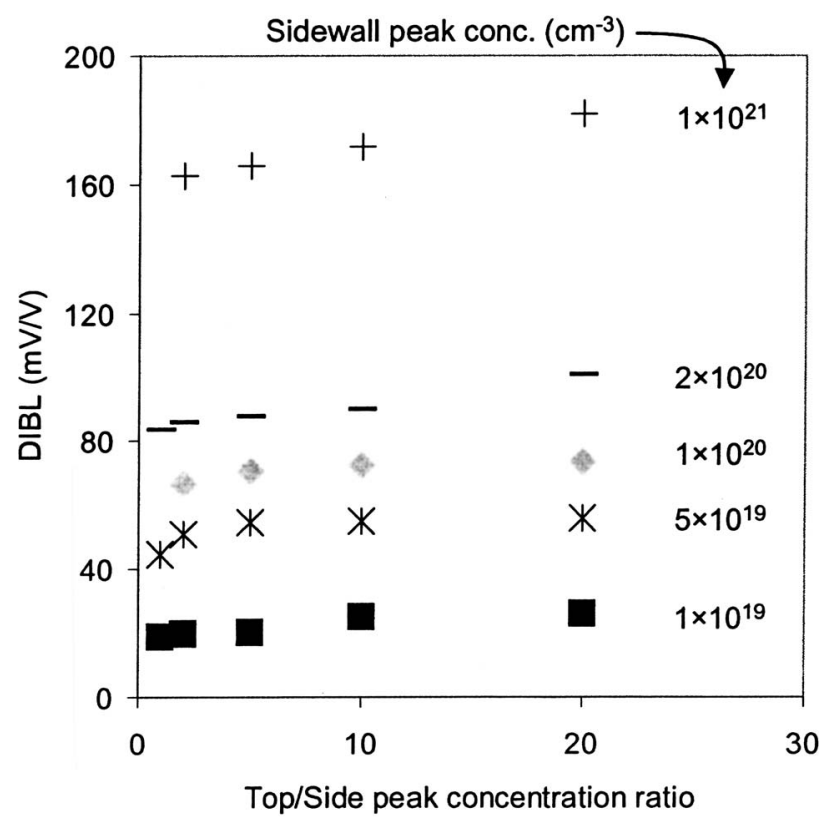

FIG. 9. Simulated DIBL versus sidewall surface concentration and the top/ side surface concentration ratio. The structure under investigation is a fully depleted FinFET of $60 \mathrm{~nm}$ fin height, $10 \mathrm{~nm}$ fin width, and $30 \mathrm{~nm}$ gate length. The supply voltage is $1 \mathrm{~V}$.

and $2.1 \mathrm{~nm}$ electrical oxide thickness. With an aspect ratio of 6 , some conclusions for this device structure may be different from those of a FinFET with an aspect ratio closer to 1 . The channel was undoped. The work function of the gate electrode was altered to counteract off-state current $\left(I_{\text {off }}\right)$ changes with doping profile variation. In this case, $I_{\text {off }}$ is fixed at $10 \mathrm{pA} / \mu \mathrm{m}$. The supply voltage is $1 \mathrm{~V}$. Gaussian doping profiles for extension regions had a fixed abruptness, variable peak active concentration, and, consequently, gatejunction overlap. The top and side surface doping profiles were varied independently to look at the trends and tradeoffs in drive current and SCE control.

Figure 9 shows simulated SCE control in the form of drain induced barrier lowering (DIBL) plotted as a function of sidewall surface concentration and of the top/side surface concentration ratio. A top/side ratio of 1 means conformal doping. For example, where the sidewall surface doping concentration is $1 \times 10^{19} \mathrm{~cm}^{-3}$ and the top/side ratio is 20 , then the top surface doping concentration is $2 \times 10^{20} \mathrm{~cm}^{-3}$. In this plot, it is clear that SCE control is a strong function of sidewall concentration (and thus of side gate-junction overlap) and is only weakly dependent on the top/side ratio.

Figure 10 shows the drive current dependency on top and sidewall doping profiles. Again, the device performance is more sensitive to sidewall concentration than top/side ratio. For all top/side concentration ratios, there is an optimum point at $5 \times 10^{19} \mathrm{~cm}^{-3}$. On the low side of this optimum, drive is limited by the source and drain resistances. Note that in this regime the drive can be optimized by increasing the top junction concentration as much as possible. On the high side of the optimum point, drive is limited by the degraded SCE control. For a fixed $I_{\text {off }}$, a worse subthreshold slope 


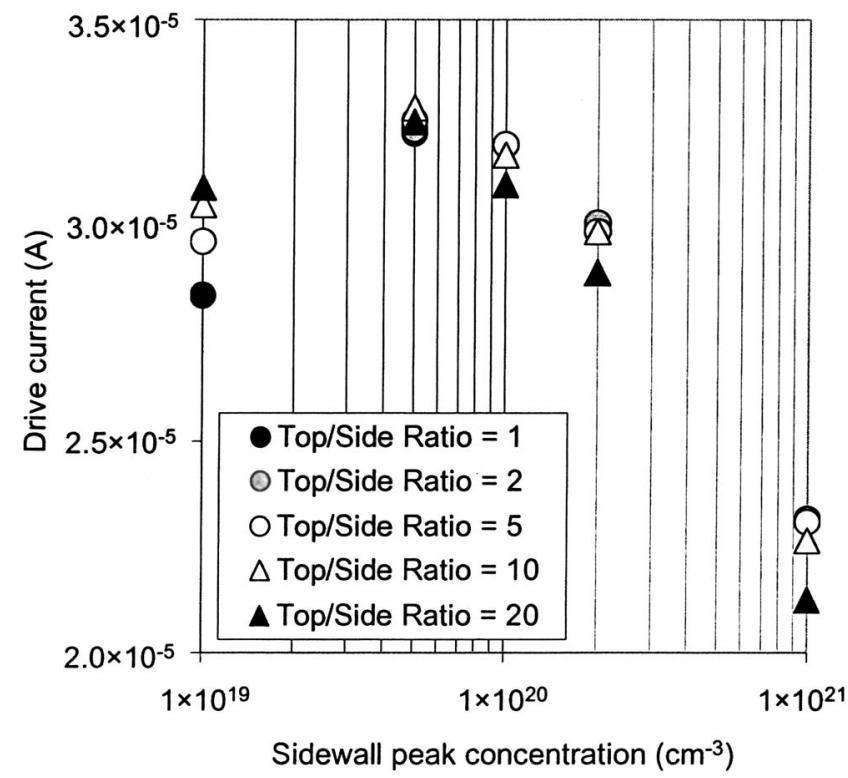

FIG. 10. Simulated drive current vs sidewall surface concentration and the top/side surface concentration ratio. The structure under investigation is a fully depleted FinFET of $60 \mathrm{~nm}$ fin height, $10 \mathrm{~nm}$ fin width, and $30 \mathrm{~nm}$ gate length. The supply voltage is $1 \mathrm{~V}$.

means a lower drive in on-state. Note that in this regime the drive can be optimized by making the doping as conformal as possible, i.e., the opposite trend to the low side of the optimum. Figure 11 combines the results of Figs. 9 and 10, as drive current is plotted versus DIBL. The points from the different top/side ratios fall on the same trend line. Thus, the optimum point does not depend on conformality.

Manufacturability of these simulated devices is an important consideration, as active doping levels $\sim 10^{21} \mathrm{~cm}^{-3}$ may

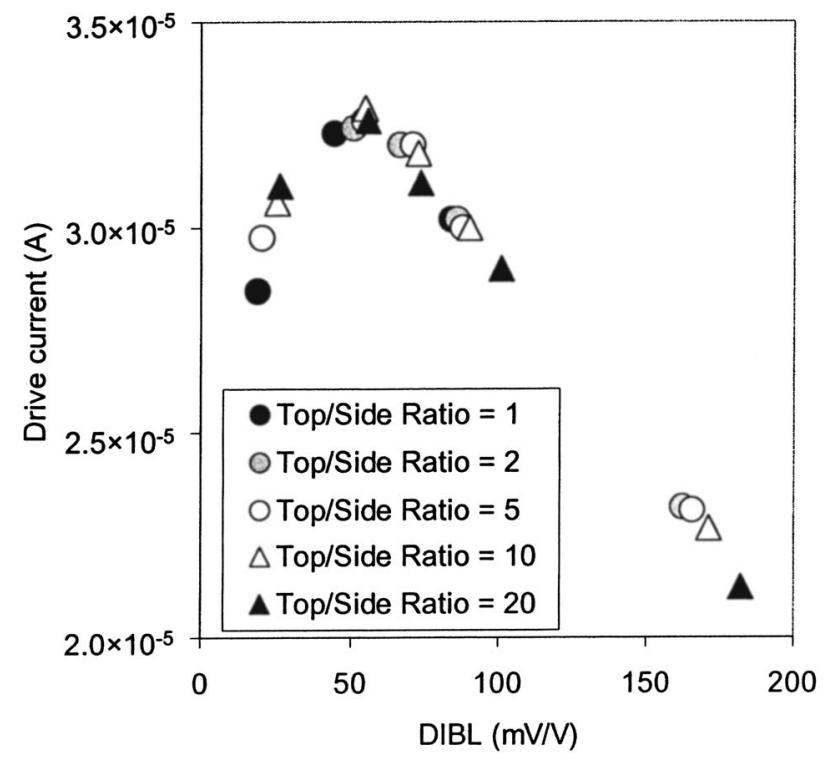

FIG. 11. Simulated drive current vs DIBL, combining the results of Figs. 9 and 10. The structure under investigation is a fully depleted FinFET of $60 \mathrm{~nm}$ fin height, $10 \mathrm{~nm}$ fin width, and $30 \mathrm{~nm}$ gate length. The supply voltage is $1 \mathrm{~V}$. be difficult to achieve due to solubility and impurity activation limitations. With the optimum sidewall surface concentration at $5 \times 10^{19} \mathrm{~cm}^{-3}$ and conventional RTA able to achieve active concentrations up to $\sim 2 \times 10^{20} \mathrm{~cm}^{-3}$, then top/side ratios of 1-4 are realistic. A higher than equilibrium solubility is achievable using alternative annealing techniques. ${ }^{9}$

We then used the arsenic SIMS profiles after RTA of Fig. 2 to define donor profiles in the 3D simulations. There were two simulated structures, namely, (A) with the $5^{\circ} / 80^{\circ}$ SIMS profiles for top/side surfaces and (B) with the $30^{\circ} / 60^{\circ}$ SIMS profiles for top/side surfaces. The top surface got twice the SIMS dose to reproduce an implant scheme whereby half the total dose is implanted from both sides of the fin, namely, a two-quad implant. Thus, the top/side dose ratios were 37 for (A) and 2.8 for (B), while the side surface peak active concentrations were $\sim 2 \times 10^{20} \mathrm{~cm}^{-3}$ for (A) and $\sim 5 \times 10^{20} \mathrm{~cm}^{-3}$ for (B). Simulation structure (A) was better than (B) in terms of simulated SCE control and drive at fixed $I_{\text {off }}$. This is not surprising when you consider that the SCE control is more quickly degraded with increased sidewall peak concentration than with increased top/side ratio (Fig. 9) and that the drive at fixed $I_{\text {off }}$ drops off for increasing sidewall peak concentration $>2 \times 10^{20} \mathrm{~cm}^{-3}$ (Fig. 10).

In conclusion, the simulated structure with less doping conformality resulting from a higher ion beam angle of incidence on sidewalls produced better electrical performance. From a FinFET integration point of view, this is a very encouraging result, as shadowing effects are likely to limit the maximum implant tilt to $<20^{\circ}$ and thus $>70^{\circ}$ on sidewalls.

\section{CONCLUSIONS}

We investigated dose retention in FinFET sidewalls as a function of ion implantation variables. Dose retention is strongly dependent on the ion beam angle of incidence and thus on the implant tilt angle. Due to possible shadowing effects, the angle of incidence on sidewalls may be in the $70^{\circ}-80^{\circ}$ range. We quantified retention for common dopant impurities and determined that there is a correlation between retained dose and ion mass, with heavier elements more likely to be incorporated. In the $70^{\circ}-80^{\circ}$ angle of incidence range, dose retentions of 5\%-15\% and 9\%-28\% were extracted for boron and antimony implants, respectively.

Differences in retained doses will lead to variations in diffusion, as most common impurities experience concentration-enhanced diffusion during RTA, and thus will affect the profile overlap with the gate. This outcome was investigated by means of $3 \mathrm{D}$ device simulation, and it was shown for fully depleted FinFETs (60 nm high, $10 \mathrm{~nm}$ wide) that drive current and SCE control are more sensitive to dose retention on sidewalls than on dopant conformality. When the sidewall peak concentration is $<10^{20} \mathrm{~cm}^{-3}$, conformality is not a benefit for drive current optimization.

\section{ACKNOWLEDGMENT}

This work has been partially funded by the European PULLNANO Integrated Project (FP6-IST-026828). 
${ }^{1}$ Y. K. Choi et al., Tech. Dig. - Int. Electron Devices Meet. 2001, 421.

${ }^{2} \mathrm{~N}$. Collaert et al., Technical Digest of the Symposium on VLSI Technology 2006, 52, ISBN: 1-4244-0005-8/06.

${ }^{3}$ M. J. H. van Dal et al., Technical Digest of the Symposium on VLSI Technology 2007, 110, ISBN: 978-4-900784-03-1.

${ }_{5}^{4}$ A. A. Khajetoorians et al., J. Appl. Phys. 101, 034505 (2007).

${ }^{5}$ A. Nylandsted Larsen, K. Kyllesbech Larsen, P. E. Andersen, and B. G. Svensson, J. Appl. Phys. 73, 691 (1993).
${ }^{6}$ A. Agarwal, H. J. Gossman, and D. J. Eaglesham, Appl. Phys. Lett. 74, 2331 (1999).

${ }^{7}$ J. F. Ziegler, SRIM (the stopping and range of ions in matter), http://www.srim.org/

${ }^{8}$ SENTAURUS DEvice User's Manual, Synopsys.

${ }^{9}$ R. Duffy, T. Dao, Y. Tamminga, K. van der Tak, F. Roozeboom, and E. Augendre, Appl. Phys. Lett. 89, 071915 (2006). 